\title{
Anthocyanins from black rice (Oryza sativa) promote immune responses in leukemia through enhancing phagocytosis of macrophages in vivo
}

\author{
MING-JEN FAN ${ }^{1,2}$, PING-HSUAN YEH ${ }^{1}$, JING-PIN LIN ${ }^{3}$, AN-CHENG HUANG ${ }^{4}$, \\ JIN-CHERNG LIEN ${ }^{5}$, HUI-YI LIN ${ }^{5}$ and JING-GUNG CHUNG ${ }^{1,6}$
}

\author{
${ }^{1}$ Department of Biotechnology, Asia University, Taichung 41354; ${ }^{2}$ Department of Medical Research, China Medical \\ University Hospital; ${ }^{3}$ Graduate Institute of Chinese Medicine, China Medical University, Taichung 40402; ${ }^{4}$ Department \\ of Nursing, St. Mary's Junior College of Medicine, Nursing and Management, Yilan 266; ${ }^{5}$ School of Pharmacy; \\ ${ }^{6}$ Department of Biological Science and Technology, China Medical University, Taichung 40402, Taiwan, R.O.C.
}

Received October 2, 2015; Accepted January 26, 2017

DOI: $10.3892 /$ etm.2017.4467

\begin{abstract}
Rice is a staple food in numerous countries around the world. Anthocyanins found in black rice have been reported to reduce the risk of certain diseases, but the effects of crude extract of anthocyanins from Asia University-selected purple glutinous indica rice (AUPGA) on immune responses have not yet been demonstrated. The current study aimed to investigate whether AUPGA treatment could affect immune responses in murine leukemia cells in vivo. Murine acute myelomonocytic leukemia WEHI-3 cells were intraperitoneally injected into normal $\mathrm{BALB} / \mathrm{c}$ mice to generate leukemia mice. A total of 50 mice were randomly divided into five groups ( $\mathrm{n}=10$ in each group) and were fed a diet supplemented with AUPGA at 0, 20,50 or $100 \mathrm{mg} / \mathrm{kg}$ for three weeks. All mice were weighed and the blood, liver and spleen were collected for further experiments. The results indicated that AUPGA did not significantly affect animal body weight, but significantly increased spleen weight $(\mathrm{P}<0.05)$ and decreased liver weight $(\mathrm{P}<0.05)$ when compared with the control group. AUPGA significantly increased the $\mathrm{T}$ cell (CD3) population at treatments of 20 and $100 \mathrm{mg} / \mathrm{kg}(\mathrm{P}<0.05)$. However, it only significantly increased the B cell (CD19) population at a treatment of $20 \mathrm{mg} / \mathrm{kg}(\mathrm{P}<0.05)$. Furthermore, AUPGA at 50 and $100 \mathrm{mg} / \mathrm{kg}$ significantly increased the monocyte (CD11b) population and the level of macrophages (Mac-3; $\mathrm{P}<0.05$ for
\end{abstract}

Correspondence to: Professor Jing-Gung Chung, Department of Biological Science and Technology, China Medical University, 91 Hsueh-Shih Road, Taichung 40402, Taiwan, R.O.C.

E-mail: jgchung@mail.cmu.edu.tw

Professor Hui-Yi Lin, School of Pharmacy, China Medical University, 91 Hsueh-Shih Road, Taichung 40402, Taiwan, R.O.C. E-mail: hylin@mail.cmu.edu.tw

Key words: crude extract of anthocyanins from black rice, WEHI-3 cells, phagocytosis, macrophage, natural killer cell both). AUPGA at 50 and $100 \mathrm{mg} / \mathrm{kg}$ significantly promoted macrophage phagocytosis in peripheral blood mononuclear cells $(\mathrm{P}<0.05)$, and all doses of AUPGA treatment significantly promoted macrophage phagocytotic activity in the peritoneum $(\mathrm{P}<0.05)$. AUPGA treatment significantly decreased natural killer cell activity from splenocytes $(\mathrm{P}<0.05)$. Finally, AUPGA treatment at $20 \mathrm{mg} / \mathrm{kg}$ treatment significantly promoted $\mathrm{T}$ cell proliferation $(\mathrm{P}<0.05)$, and treatment at 50 and $100 \mathrm{mg} / \mathrm{kg}$ significantly decreased $\mathrm{B}$ cell proliferation compared with the control group $(\mathrm{P}<0.05)$.

\section{Introduction}

Acute myelomonocytic leukemia, a clonal disorder of hematopoiesis, is a genetically heterogeneous disease that is characterized by the uncontrolled proliferation and accumulation of immature and dysfunctional hematopoietic progenitors $(1,2)$. One quarter of adults diagnosed with acute myeloid leukemia (AML) are known to have preceding hematologic disorders (3). Currently, cytotoxic chemotherapy is widely used for the treatment of AML patients (4). It has been reported that post-remission therapy is essential for AML patients with complete hematologically-defined remission. (5). It has also been reported that increased consumption of fruits and vegetables can decrease the risk of cancer (6), cardiovascular disease and atherosclerosis in humans (7).

Previous studies have reported that dietary agents are able to safely modulate physiological function and enhance anti-cancer activity (8-10). Numerous studies have demonstrated that a diet rich in whole grains may decrease the risk of certain chronic diseases, such as obesity (11), cardiovascular disease $(12,13)$, diabetes (14) and certain cancer types $(14,15)$. It has been reported that regions where rice is a staple food have a low prevalence of certain chronic diseases due to rice containing antioxidant compounds, such as anthocyanins (16). It was reported that Oryza sativa japonica variety Dongjin rice (the parental plant of the resveratrol-enriched rice DJ-526), is rich in fiber and polyphenols, and is reported to have an anti-obesity effect (17). Numerous reports have indicated 
that the consumption of refined grains is associated with a higher risk of cancer $(18,19)$. However, previous results have also suggested that dietary anthocyanins may reduce the risk of chronic diseases, including cancers (20). Furthermore, black rice anthocyanins have been reported to possess anti-metastasis potential in human breast cancer cells in vivo and in vitro (21). Anti-angiogenesis and anti-cancer invasion activities of anthocyanins have also been identified in vitro and in vivo $(22,23)$. The current authors recently demonstrated that anthocyanins from AUPGA suppressed human oral cancer CAL 27 cell metastasis in vitro (24).

The effects of anthocyanins on immune responses have not previously been demonstrated. Thus, in the current study, the effects of Asia University-selected purple glutinous indica rice (AUPGA) on the immune responses in leukemia mice were investigated. BALB/c mice were injected with WEHI-3 cells to generate leukemia mice, which were then treated orally with AUPGA. The immune responses were evaluated in vivo. AUPGA promoted immune responses in leukemia BALB/c mice, including an increase in macrophage phagocytosis and natural killer (NK) cell activities.

\section{Materials and methods}

Materials and reagents. Crude extract of anthocyanins from the rice bran of AUPGA was provided by Dr Hui-Yi Lin (China Medical University, Taichung, Taiwan). The composition of this extract was analyzed and cyanidin-3-O-glucoside (an anthocyanin) was the only component found. AUPGA was dissolved in dimethyl sulfoxide at $1 \%$ stock solution and kept at $-20^{\circ} \mathrm{C}$ in a $50-\mathrm{ml}$ tube covered with aluminum paper to avoid contact with light. RPMI-1640 cell culture medium, fetal bovine serum (FBS), L-glutamine, penicillin and streptomycin were obtained from Gibco (Thermo Fisher Scientific, Inc., Waltham, MA, USA). All antibodies were obtained from Santa Cruz Biotechnology, Inc. (Dallas, TX, USA).

Cell culture. Murine acute myelomonocytic leukemia WEHI-3 cell line was obtained from the Food Industry Research and Development Institute (Hsinchu, Taiwan). Cells were cultured in $75-\mathrm{cm}^{3}$ flasks in RPMI-1640 medium supplemented with $10 \% \mathrm{FBS}, 100 \mathrm{units} / \mathrm{ml}$ penicillin, $100 \mu \mathrm{g} / \mathrm{ml}$ streptomycin and $2 \mathrm{mM}$ L-glutamine, and maintained at $37^{\circ} \mathrm{C}$ in a humidified atmosphere of $5 \% \mathrm{CO}_{2}(25,26)$. Cells were allowed to equilibrate for $24 \mathrm{~h}$ before being used.

Male BALB/c mice. A total of 50 eight-week-old male BALB/c mice, weighing 22-25 g each, were purchased from the National Laboratory Animal Center (Taipei, Taiwan) and housed in stainless steel, mesh-bottomed cages. Mice were kept under specified pathogen-free conditions in the animal center of China Medical University (Taichung, Taiwan). All experiments were carried out in accordance with the Institutional Guidelines for Animal Welfare of China Medical University and were approved by the Institutional Animal Care and Use Committee of China Medical University, as previously described $(25,26)$.

Treatment of animals with AUPGA. BALB/c mice were randomly divided into five groups $(n=10$ per group).
Groups II-V were intraperitoneally injected with $10^{6}$ WEHI-3 leukemia cells. Group I mice received a normal diet ad libitum as the control. Group II mice received a normal diet ad libitum with $100 \mu \mathrm{l}$ olive oil by oral gavage. Group III mice received a normal diet ad libitum and AUPGA (20 mg/kg with $100 \mu \mathrm{l}$ olive oil by oral gavage). Group IV mice received a normal diet ad libitum and AUPGA (50 mg/kg with $100 \mu$ l olive oil by oral gavage). Group $\mathrm{V}$ mice received a normal diet ad libitum and AUPGA (100 mg/kg with $100 \mu 1$ olive oil by oral gavage). AUPGA in olive oil was administered by oral gavage once every three days for 21 days and all mice were weighed throughout the oral treatment. At the end of treatment, all mice were weighed and sacrificed by euthanasia with $\mathrm{CO}_{2}$, as previously described $(25,26)$.

Immunofluorescence staining for cell surface markers. The blood and spleen of each mouse was collected. Splenocytes were isolated from the spleen in order to evaluate NK cell activity, as previously described $(25,26)$. To analyze blood samples $(0.2 \mathrm{ml}$ each) for cell markers, red blood cells were lysed using 1X Pharm Lyse ${ }^{\mathrm{TM}}$ lysing buffer (BD Pharmingen, San Diego, CA, USA), according to the manufacturer's instructions. After centrifugation at $1,500 \mathrm{x} g$ for $15 \mathrm{~min}$ at $4^{\circ} \mathrm{C}$, white blood cells were collected and stained with phycoerythrin (PE)-labeled anti-mouse CD3 (BD553062, BD Biosciences, San Jose, CA, USA), PE-labeled anti-mouse CD19 (BD553786, BD Biosciences), fluroscein isothiocyanate (FITC)-labeled anti-mouse CD11b (BD553310, BD Biosciences) and FITC-labeled anti-mouse Mac-3 (BD553324, BD Biosciences) antibodies (the dilution of each antibody was 1:12) for $30 \mathrm{~min}$ at $4^{\circ} \mathrm{C}$. The cells were washed with PBS and analyzed for cell marker population by flow cytometry, as previously described $(25,26)$.

Flow cytometric assay for macrophage phagocytosis. Macrophages were obtained from the peripheral blood mononuclear cells (PBMCs) and peritoneum of each mouse, as previously described $(21,23)$. Isolated macrophages were maintained in the FACS tube (Falcon 352052,BD Biosciences; $100 \mu 1$ PBMCs/tube, $1 \mathrm{ml}$ peritoneal fluid/tube) and $10 \mu 1$ Escherichia coli-FITC was added to each well, based on the PHAGOTEST ${ }^{\circledR}$ kit manufacturer instructions (BD Biosciences). All samples were analyzed for phagocytosis by flow cytometry and quantified using CellQuest software (version 5.2.1; BD Biosciences), as previously described $(25,26)$.

Flow cytometric assay for NK cell cytotoxic activity. Splenocytes $\left(2.5-5 \times 10^{5}\right.$ cells/well) from each mouse were maintained on a 96-well plate containing $100 \mu 1$ RPMI-1640 medium in each well. YAC-1 target cells $\left(1 \times 10^{4}\right.$ cells) in serum-free RPMI-1640 medium and PKH-67/Dil.C buffer (Sigma-Aldrich; Merck KGaA, Darmstadt, Germany) were added to each well, based on the manufacturer's instructions, to form target:effector ratios of 25:1 and 50:1 (splenocytes:YAC-1 target cells). All samples were mixed well for $2 \mathrm{~min}$, then $2 \mathrm{ml}$ PBS was added to each well for $1 \mathrm{~min}$. Next, $4 \mathrm{ml}$ medium was added to each well and the cells were incubated for $10 \mathrm{~min}$. All steps were performed at $25^{\circ} \mathrm{C}$. The cells were centrifuged at $25^{\circ} \mathrm{C}$ at $290 \mathrm{x} \mathrm{g}$ for $2 \mathrm{~min}$. NK cell cytotoxic activity was assayed by flow cytometry, as previously described (25-27). 
A
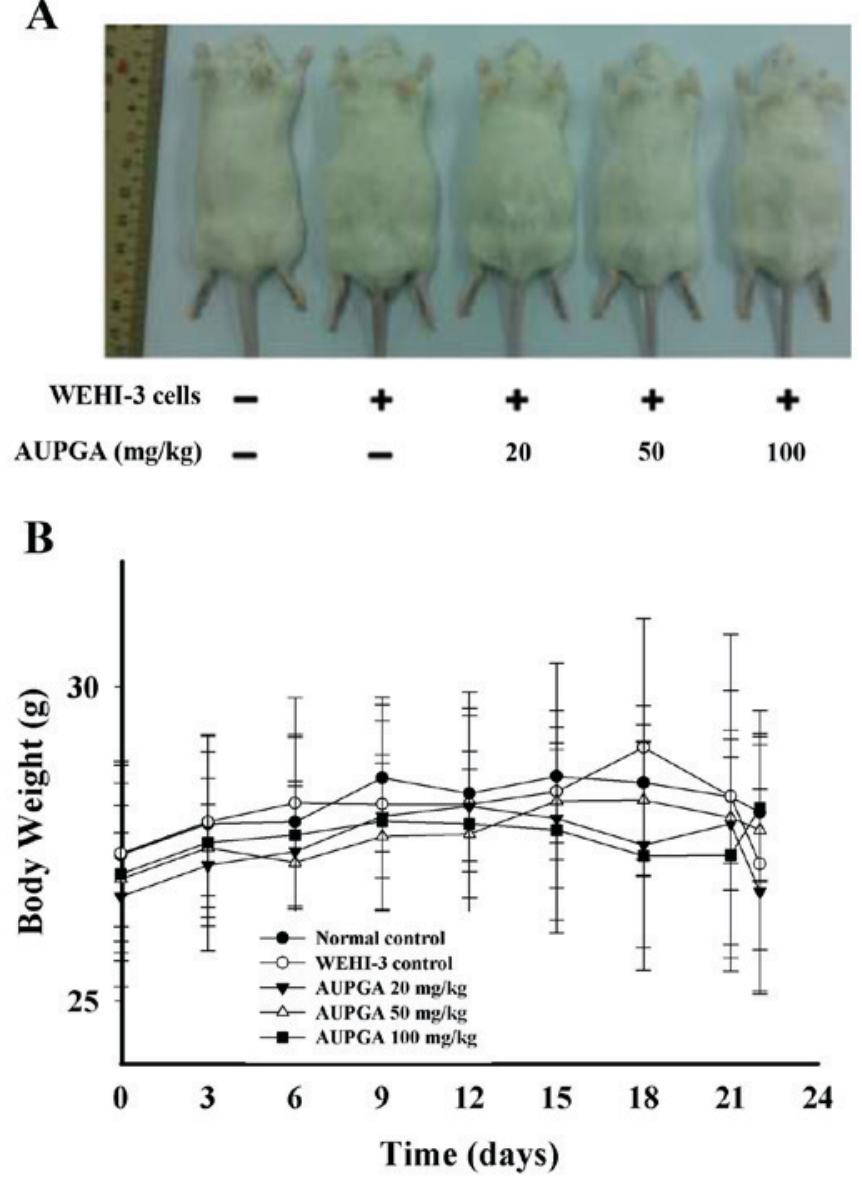

C
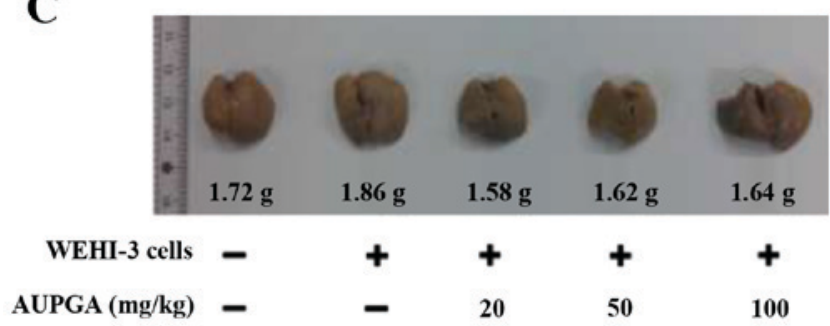

D

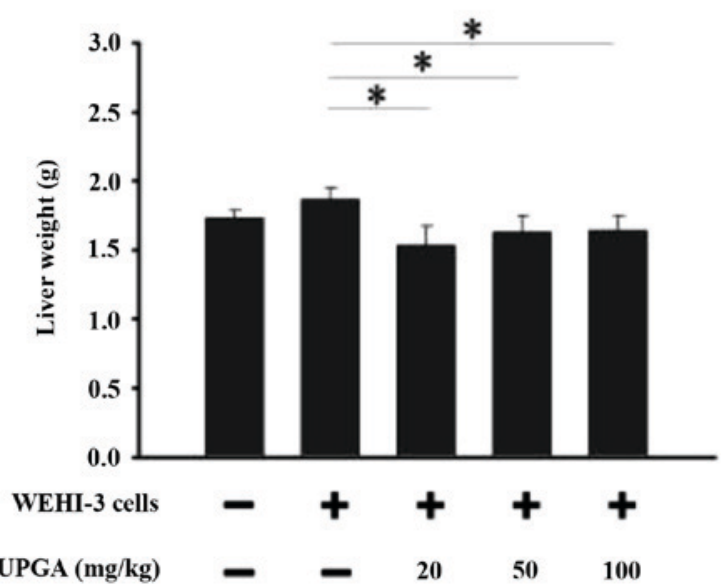

Figure 1. Effect of AUPGA treatment on the body, liver and spleen weights of leukemia BALB/c mice. All animals were treated for 22 days. (A) Representative images of the mouse bodies at the end of the treatment period. (B) Total body weight throughout the treatment period (measured every three days). (C) Representative images of the mouse livers at the end of the treatment period. (D) Weights of mouse livers at the end of the treatment period. ${ }^{*} \mathrm{P}<0.05$ vs. AUPGA-untreated leukemia mice group.
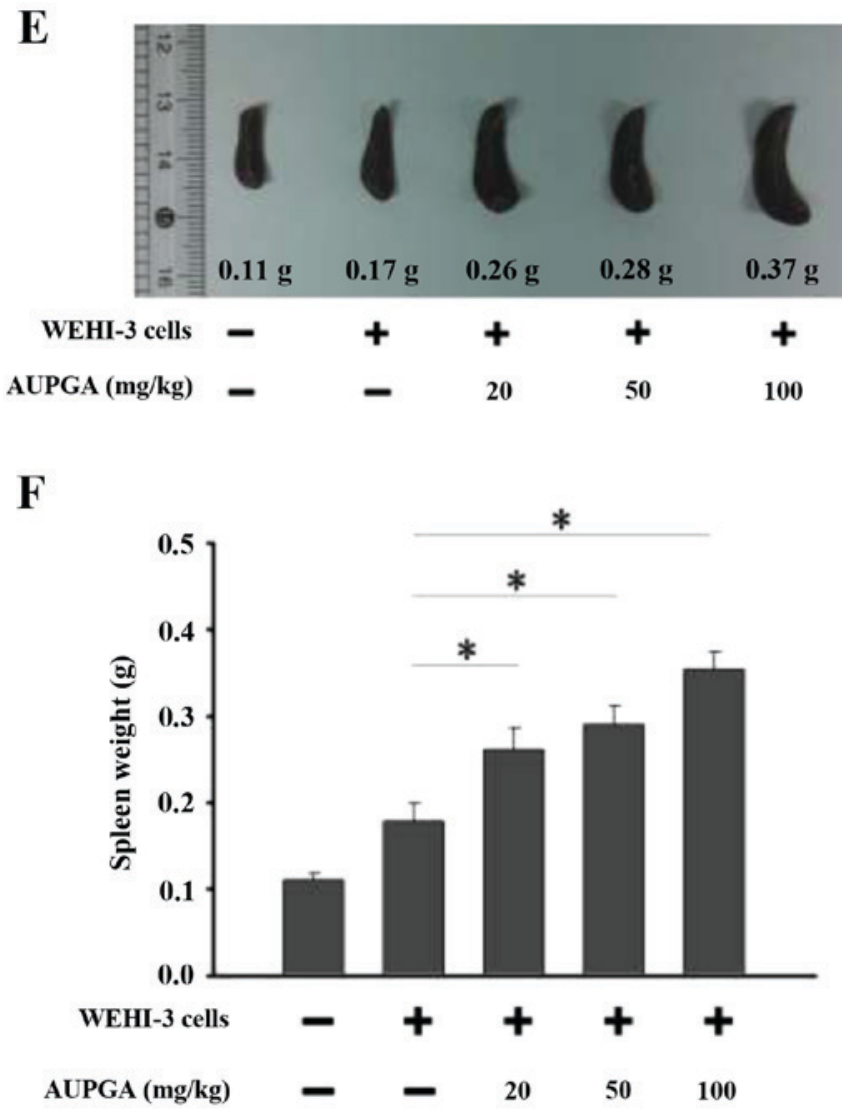

Figure 1. Continued. (E) Representative images of the mouse spleens at the end of the treatment period. (F) Weights of mouse spleens at the end of the treatment period. " $\mathrm{P}<0.05$ vs. AUPGA-untreated leukemia mice group. AUPGA, Asia University selected purple glutinous indica rice.

Assay for T and B cell proliferation. Splenocytes ( $10^{5}$ cells/well) were maintained in a 96-well plate with $100 \mu \mathrm{l}$ RPMI-1640 medium in each well. For B cell proliferation analysis, $1 \mu \mathrm{g} / \mathrm{ml}$ lipopolysaccharide (LPS) was added to the well to stimulate cells for three days. For T cell proliferation analysis, $1 \mu \mathrm{g} / \mathrm{ml}$ concanavalin A was added to the well to stimulate cells for five days. At the end of incubation, each sample was assayed for T or B cell proliferation using a CellTiter 96 Aqueous One Solution Cell Proliferation Assay kit (Promega Corporation, Madison, WI, USA), as previously described $(25,26)$.

Statistical analysis. Data are presented as the mean \pm standard deviation. Differences between the control and AUPGA-treated groups were analyzed using the Student's t-test and SigmaPlot software version 10.0 (Systat Software, Inc., London, UK). $\mathrm{P}<0.05$ was considered to indicate a statistically significant difference.

\section{Results}

Effects of AUPGA treatment on the body, liver and spleen weights of leukemia BALB/c mice. Groups II-V were treated with WEHI-3 to generate leukemia and Group I was a normal control. Group II was a WEHI-3 control without AUPGA treatment, while Groups III, IV and V were treated with AUPGA (20, 50 and $100 \mathrm{mg} / \mathrm{kg}$, respectively) for 22 days. During the experimental period, all mice were weighed every three days. 

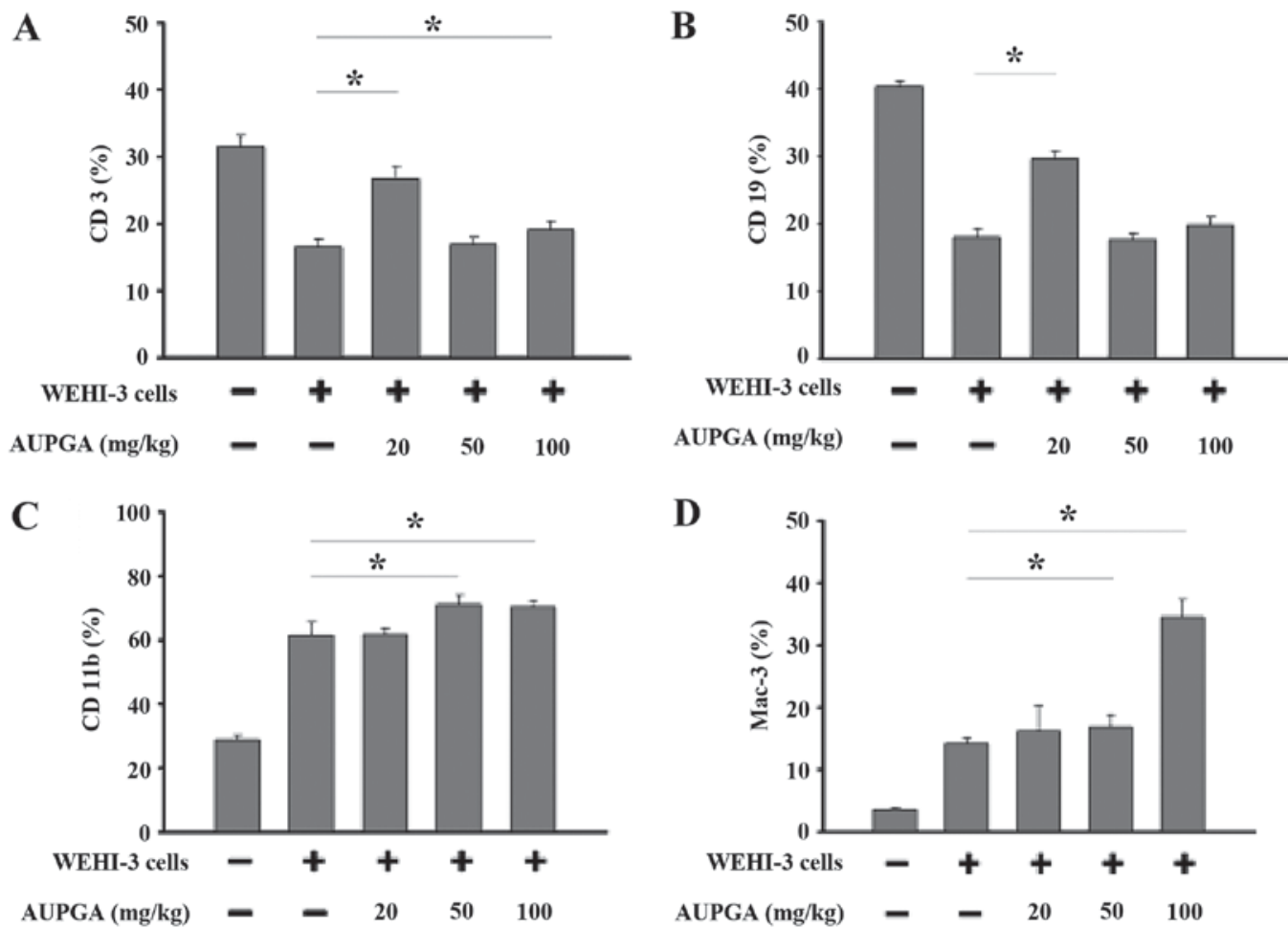

Figure 2. Effects of AUPGA treatment on cell markers of white blood cells from leukemia BALB/c mice. Blood was collected from mice and analyzed for cell markers (A) CD3, (B) CD19, (C) CD11b and (D) Mac-3 by flow cytometry. "P<0.05 vs. AUPGA-untreated leukemia mice group. AUPGA, Asia University selected purple glutinous indica rice.

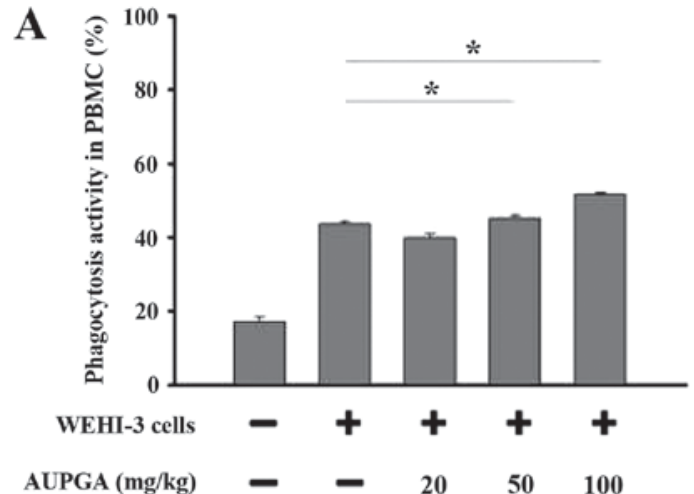

B

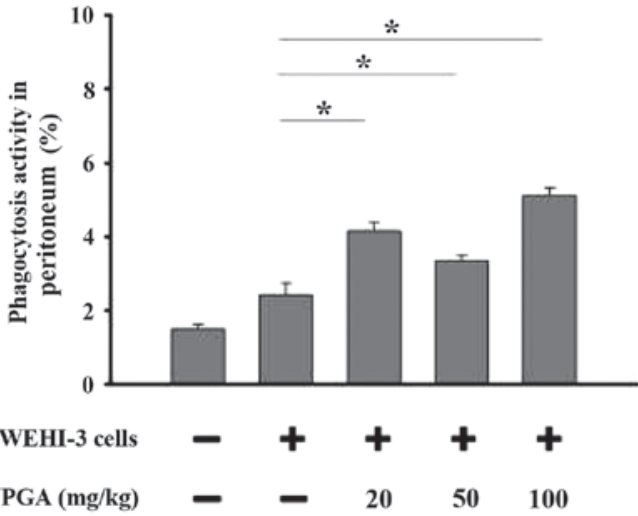

Figure 3. Effect of AUPGA treatment on macrophage phagocytosis in the $\mathrm{PBMC}$ and peritoneum of leukemia BALB/c mice. Blood samples were collected, then macrophages were isolated from the (A) PBMC and (B) peritoneum of each mouse. Macrophage phagocytosis activity was assayed by flow cytometry and quantified using CellQuest software. "P $<0.05$ vs. AUPGA-untreated leukemia mice group. AUPGA, Asia University selected purple glutinous indica rice; PBMC, peripheral blood mononuclear cell.
Representative images of the animals, livers and spleens, as well as the weights of each, are presented in Fig. 1A-F. These results demonstrated that AUPGA did not affect the appearance of the mice (Fig. 1A) or cause any significant change in body weight (Fig. 1B) in the mice of each group. However, the liver weight was significantly decreased $(\mathrm{P}<0.05$; Fig. $1 \mathrm{C}$ and $\mathrm{D})$ and the spleen weight was significantly increased $(\mathrm{P}<0.05$; Fig. 1E and F) as compared with the AUPGA-untreated leukemia mice.

Effects of AUPGA treatment on cell marker levels in leukemia $B A L B / c$ mice. White blood cells were isolated from each group, and the levels of cell markers CD3, CD19, CD11b and Mac-3 were measured by flow cytometry. As shown in Fig. 2A, AUPGA treatment at 20 or $100 \mathrm{mg} / \mathrm{kg}$ significantly increased the T cell (CD3) population compared with AUPGA-untreated leukemia mice $(\mathrm{P}<0.05)$. AUPGA treatment at $20 \mathrm{mg} / \mathrm{kg}$ also led to a significant increase in the B cell (CD19) population as compared with AUPGA-untreated leukemia mice $(\mathrm{P}<0.05$; Fig. 2B). AUPGA treatment at 50 or $100 \mathrm{mg} / \mathrm{kg}$ led to a significant increase in both the monocyte (CD11b) population $(\mathrm{P}<0.05$; Fig. 2C) and the levels of macrophage (Mac-3) $(\mathrm{P}<0.05$; Fig. 2D).

Effect of AUPGA treatment on macrophage phagocytosis in the PBMCs and peritoneum of leukemia BALB/c mice. Cells were collected from the PBMCs and peritoneum of each group. The percentage of macrophage phagocytosis was analyzed by flow cytometry. As shown in Fig. 3A, AUPGA treatment at 50 and $100 \mathrm{mg} / \mathrm{kg}$ significantly promoted macrophage phagocytosis in the PBMCs as compared with AUPGA-untreated leukemia 

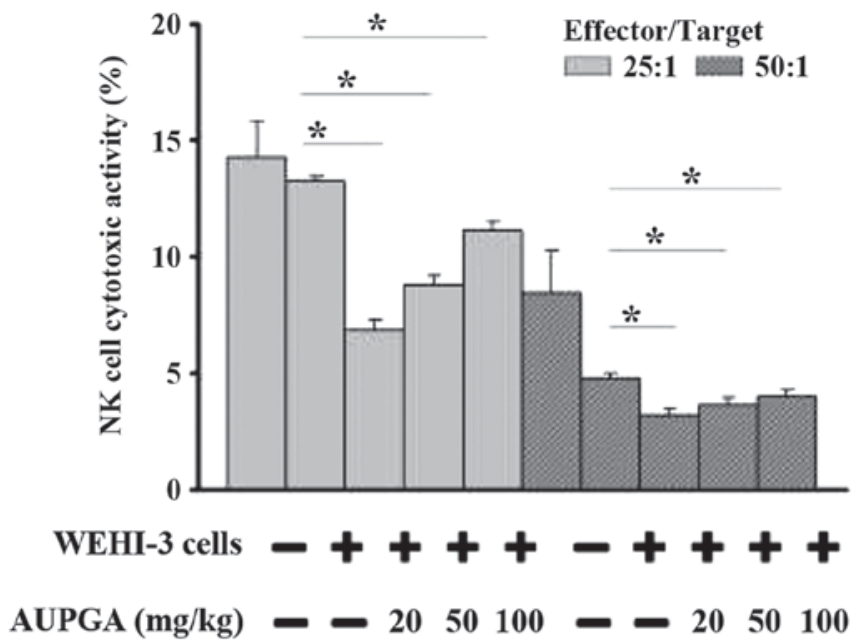

Figure 4. Effect of AUPGA treatment on the cytotoxic activity of NK cells from leukemia BALB/c mice. Splenocytes were cultured in 96-well plates and target YAC-1 cells were added. NK cell cytotoxic activity was measured using flow cytometry. "P<0.05 vs. AUPGA-untreated leukemia mice group. AUPGA, Asia University selected purple glutinous indica rice; NK, natural killer.
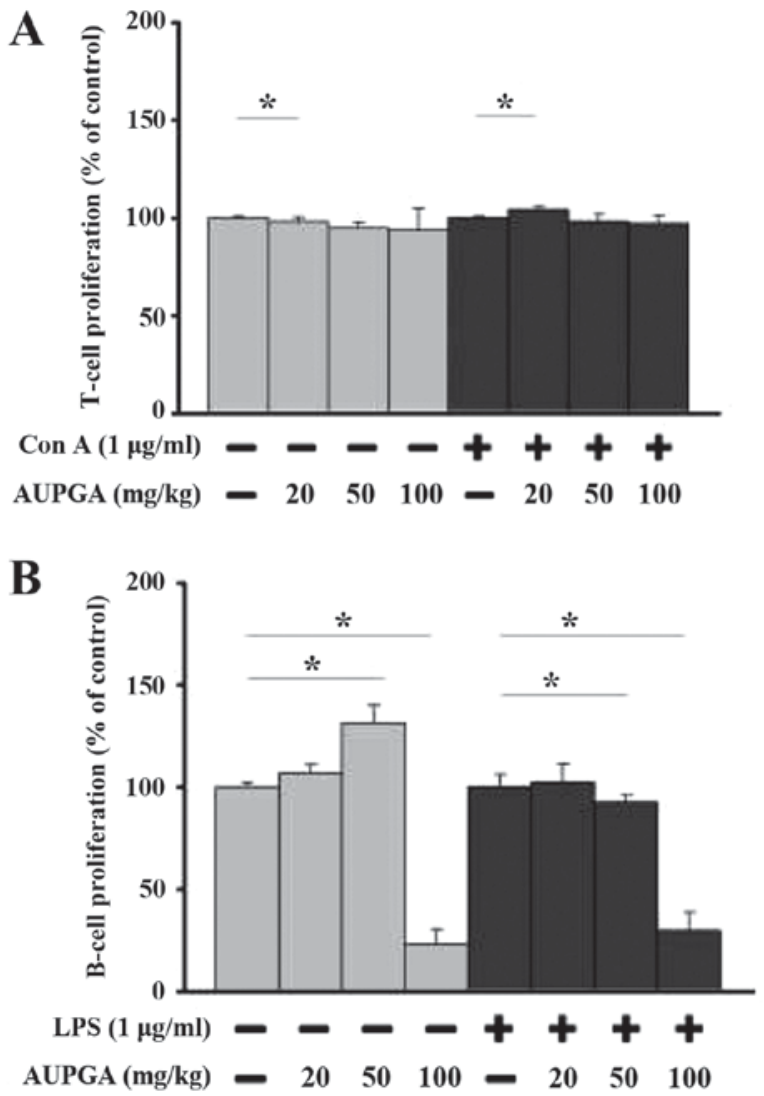

Figure 5. Effect of AUPGA treatment on $\mathrm{T}$ and $\mathrm{B}$ cell proliferation in leukemia BALB/c mice. (A) T cells were pretreated with or without Con A, then cell proliferation was analyzed by flow cytometry. (B) B cells were pretreated with or without LPS, then cell proliferation was analyzed by flow cytometry. "P<0.05 vs. AUPGA-untreated leukemia mice group. AUPGA, Asia University selected purple glutinous indica rice; LPS, lipopolysaccharide; Con $\mathrm{A}$, concanavalin $\mathrm{A}$.

mice $(\mathrm{P}<0.05)$. All doses of AUPGA treatment significantly promoted macrophage phagocytic activity in the peritoneum as compared with AUPGA-untreated leukemia mice $(\mathrm{P}<0.05$; Fig. 3B).

Effect of AUPGA treatment on the cytotoxic activity of NK cells from leukemia BALB/c mice. YAC-1 targets cells were added to splenocytes from mice in each group. NK cell activity was then evaluated using flow cytometry. As shown in Fig. 4, all doses of AUPGA treatment significantly decreased NK cell cytotoxic activity as compared with AUPGA-untreated leukemia mice $(\mathrm{P}<0.05)$.

Effect of AUPGA treatment on $T$ and $B$ cell proliferation from leukemia $B A L B / c$ mice. Splenocytes from each group were used for T and B cell proliferation assays. AUPGA treatment at $20 \mathrm{mg} / \mathrm{kg}$ significantly promoted $\mathrm{T}$ cell proliferation with or without concanavalin A pretreatment $(\mathrm{P}<0.05$; Fig. $5 \mathrm{~A})$, and AUPGA treatment at 50 and $100 \mathrm{mg} / \mathrm{kg}$ significantly decreased $B$ cell proliferation with or without LPS pretreatment $(\mathrm{P}<0.05$; Fig. 5B) as compared with AUPGA-untreated leukemia mice.

\section{Discussion}

Plant-derived bioactive compounds, such as paclitaxel from Taxus brevifolia and camptothectin from Camptotheca acuminate, are commonly used in the clinical treatment of cancer $(28,29)$. In 2006, the Food and Drug Administration in the USA approved the marketing of Veregen ${ }^{\circledR}$ (the first botanical product to be approved as a drug) for treatment of external genital and perianal warts (30). However, to date, there have been few studies regarding the biological activities of AUPGA in animal models. In particular, the effects of AUPGA on immune responses in vivo have not been elucidated. Thus, the current study aimed to investigate how AUPGA treatment affected immune responses in leukemia BALB/c mice in vivo.

Normal BALB/c mice were intraperitoneally injected with WEHI-3 cells to induce leukemia. Mice were then divided into groups and were orally treated with or without AUPGA once every three days for 22 days. It was found that AUPGA had no significant effect on body weight in the leukemia mice but decreased the liver weight and increased the spleen weight as compared with the AUPGA-untreated leukemia mice. It was also found that AUPGA promoted the T cell (CD3) population at 20 and $100 \mathrm{mg} / \mathrm{kg}$ treatments, but only $20 \mathrm{mg} / \mathrm{kg}$ of AUPGA treatment led to an increase in the B cell (CD19) population. AUPGA treatment at 50 or $100 \mathrm{mg} / \mathrm{kg}$ led to an increase in the monocyte (CD11b) population and the levels of macrophage (Mac-3). It has previously been reported that it is possible for macrophages to kill and eliminate cancer cells (31-33). Thus, it was proposed by the current authors that the activation of macrophages by AUPGA may reduce cancer risk.

Macrophages serve a key function in the response to antigens in the animal body and are able to destroy target cells in vivo (24). The current study demonstrated that AUPGA treatment at 50 or $100 \mathrm{mg} / \mathrm{kg}$ significantly promoted macrophage phagocytosis in samples from the PBMCs, and all tested doses of AUPGA treatment significantly promoted macrophage phagocytic activity in samples from the peritoneum. All tested doses of AUPGA treatment significantly decreased NK cell activity. However, this observed alteration in NK cell function is also a decreased immune response. Thus, AUPGA may have a cell specificity 
that requires further investigation in the future. Furthermore, AUPGA treatment at $20 \mathrm{mg} / \mathrm{kg}$ significantly promoted $\mathrm{T}$ cell proliferation and treatment at 50 or $100 \mathrm{mg} / \mathrm{ml}$ significantly decreased B cell proliferation, which was stimulated by LPS. Oral intake of LPS has been reported to be effective in preventing certain diseases (34). Further investigations are required in this area, including in vivo studies for WEHI-3 cell xenograft mice treated with AUPGA by oral gavage.

In conclusion, the present study indicated that the crude extract of anthocyanins from the rice bran of AUPGA did not alter the body weight of leukemia BALB/c mice in vivo, but did promote CD3 (T cell), CD19 (B cell), CD11b (monocyte) and Mac-3 (macrophage) populations in leukemia mice. Furthermore, AUPGA treatment promoted macrophage phagocytosis and decreased NK cell activity in leukemia $\mathrm{BALB} / \mathrm{c}$ mice in vivo.

\section{Acknowledgements}

This study was supported by a grant from China Medical University, Taichung, Taiwan (grant no. CMU103-ASIA-01).

\section{References}

1. Cancer Genome Atlas Research Network: Genomic and epigenomic landscapes of adult de novo acute myeloid leukemia. N Engl J Med 368: 2059-2074, 2013.

2. Thiede C: Mutant DNMT3A: Teaming up to transform. Blood 119: 5615-5617, 2012.

3. Juliusson G, Antunovic P, Derolf A, Lehmann S, Möllgård L, Stockelberg D, Tidefelt U, Wahlin A and Höglund M: Age and acute myeloid leukemia: Real world data on decision to treat and outcomes from the Swedish Acute Leukemia Registry. Blood 113: 4179-4187, 2009.

4. Du Y, Lu F, Li P, Ye J, Ji M, Ma D and Ji C: SMG1 acts as a novel potential tumor suppressor with epigenetic inactivation in acute myeloid leukemia. Int J Mol Sci 15: 17065-17076, 2014.

5. Gundermann S, Klinker E, Kimmel B, Flierl U, Wilhelm M, Einsele $\mathrm{H}$ and Kunzmann V: A comprehensive analysis of primary acute myeloid leukemia identifies biomarkers predicting susceptibility to human allogeneic V $\gamma 9 \mathrm{~V} \delta 2 \mathrm{~T}$ T cells. J Immunother 37: 321-330, 2014.

6. Soerjomataram I, Oomen D, Lemmens V, Oenema A, Benetou V, Trichopoulou A, Coebergh JW, Barendregt J and de Vries E: Increased consumption of fruit and vegetables and future cancer incidence in selected European countries. Eur J Cancer 46: 2563-2580, 2010.

7. Pratheeshkumar P, Sreekala C, Zhang Z, Budhraja A, Ding S, Son YO, Wang X, Hitron A, Hyun-Jung K, Wang L, et al: Cancer prevention with promising natural products: Mechanisms of action and molecular targets. Anticancer Agents Med Chem 12: $1159-1184,2012$

8. Hatcher H, Planalp R, Cho J, Torti FM and Torti SV: Curcumin: From ancient medicine to current clinical trials. Cell Mol Life Sci 65: 1631-1652, 2008.

9. Liu BL, Zhang X, Zhang W and Zhen HN: New enlightenment of French Paradox: Resveratrol's potential for cancer chemoprevention and anti-cancer therapy. Cancer Biol Ther 6: 1833-1836, 2007.

10. Salvioli S, Sikora E, Cooper EL and Franceschi C: Curcumin in cell death processes: A challenge for CAM of age-related pathologies. Evid Based Complement Alternat Med 4: 181-190, 2007.

11. Misra A, Rastogi K and Joshi SR: Whole grains and health: Perspective for Asian Indians. J Assoc Physicians India 57: 155-162, 2009

12. Flint AJ, Hu FB, Glynn RJ, Jensen MK, Franz M, Sampson L and Rimm EB: Whole grains and incident hypertension in men. Am J Clin Nutr 90: 493-498, 2009.

13. Hu FB: Diet and lifestyle influences on risk of coronary heart disease. Curr Atheroscler Rep 11: 257-263, 2009.
14. Maki KC, Beiseigel JM, Jonnalagadda SS, Gugger CK, Reeves MS, Farmer MV, Kaden VN and Rains TM: Whole-grain ready-to-eat oat cereal, as part of a dietary program for weight loss, reduces low-density lipoprotein cholesterol in adults with overweight and obesity more than a dietary program including low-fiber control foods. J Am Diet Assoc 110: 205-214, 2010.

15. Haas P, Machado MJ, Anton AA, Silva AS and de Francisco A: Effectiveness of whole grain consumption in the prevention of colorectal cancer: Meta-analysis of cohort studies. Int J Food Sci Nutr 6: 1-13, 2009.

16. Goufo P and Trindade H: Rice antioxidants: Phenolic acids, flavonoids, anthocyanins, proanthocyanidins, tocopherols, tocotrienols, $\gamma$-oryzanol, and phytic acid. Food Sci Nutr 2: 75-104, 2014

17. Park SY, Lee SM, Yeo Y, Kweon SJ, Cho HS and Kim JK: Comparison of the nutritional compositions of insect-resistant and glufosinate-tolerant rice and conventional rice. J Appl Biol Chem 56: 5-9, 2013.

18. Chan JM, Wang F and Holly EA: Whole grains and risk of pancreatic cancer in a large population-based case-control study in the San Francisco Bay area, California. Am J Epidemiol 166: 1174-1185, 2007.

19. Garavello W, Lucenteforte E, Bosetti C and La Vecchia C: The role of foods and nutrients on oral and pharyngeal cancer risk. Minerva Stomatol 58: 25-34, 2009.

20. Okarter N and Liu RH: Health benefits of whole grain phytochemicals. Crit Rev Food Sci Nutr 50: 193-208, 2010.

21. Luo LP, Han B, Yu XP, Chen XY, Zhou J, Chen W, Zhu YF, Peng XL, Zou Q and Li SY: Anti-metastasis activity of black rice anthocyanins against breast cancer: Analyses using an ErbB2 positive breast cancer cell line and tumoral xenograft model. Asian Pac J Cancer Prev 15: 6219-6225, 2014.

22. Favot L, Martin S, Keravis T, Andriantsitohaina R and Lugnier C: Involvement of cyclin-dependent pathway in the inhibitory effect of delphinidin on angiogenesis. Cardiovasc Res 59: 479-487, 2003.

23. Syed DN, Afaq F, Sarfaraz S, Khan N, Kedlaya R, Setaluri V and Mukhtar H: Delphinidin inhibits cell proliferation and invasion via modulation of Met receptor phosphorylation. Toxicol Appl Pharmacol 231: 52-60, 2008

24. Fan MJ, Wang IC, Hsiao YT, Lin HY, Tang NY, Hung TC, Quan C, Lien JC and Chung JG: Anthocyanins from black rice (Oryza sativa L.) demonstrate antimetastatic properties by reducing MMPs and NF- $\kappa \mathrm{B}$ expressions in human oral cancer CAL 27 cells. Nutr Cancer 67: 327-338, 2015.

25. Chueh FS, Lin JJ, Lin JP, Yu FS, Lin JH, Ma YS, Huang YP, Lien JC and Chung JG: Crude extract of Polygonum cuspidatum promotes immune responses in leukemic mice through enhancing phagocytosis of macrophage and natural killer cell activities in vivo. In Vivo 29: 255-261, 2015.

26. Yu FS, Yang JS, Yu CS, Chiang JH, Lu CC, Chung HK, Yu CC, Wu CC, Ho HC and Chung JG: Safrole suppresses murine myelomonocytic leukemia WEHI-3 cells in vivo, and stimulates macrophage phagocytosis and natural killer cell cytotoxicity in leukemic mice. Environ Toxicol 28: 601-608, 2013.

27. Lu HF, Tung WL, Yang JS, Huang FM, Lee CS, Huang YP, Liao WY, Chen YL and Chung JG: In vitro suppression of growth of murine WEHI-3 leukemia cells and in vivo promotion of phagocytosis in a leukemia mice model by indole-3-carbinol. J Agric Food Chem 60: 7634-7643, 2012.

28. Oberlies NH and Kroll DJ: Camptothecin and taxol: Historic achievements in natural products research. J Nat Prod 67: 129-135, 2004.

29. Wall ME: Camptothecin and taxol: Discovery to clinic. Med Res Rev 18: 299-314, 1998.

30. Meltzer SM, Monk BJ and Tewari KS: Green tea catechins for treatment of external genital warts. Am J Obstet Gynecol 200: 233.e1-7, 2009.

31. Inui T, Kubo K, Kuchiike D, Uto Y, Nishikata T, Sakamoto N and Mette M: Oral colostrum macrophage-activating factor for serious infection and chronic fatigue syndrome: Three case reports. Anticancer Res 35: 4545-4549, 2015.

32. Inui T, Kuchiike D, Kubo K, Mette M, Uto Y, Hori H and Sakamoto N: Clinical experience of integrative cancer immunotherapy with GcMAF. Anticancer Res 33: 2917-2919, 2013.

33. Mills CD and Ley K: M1 and M2 macrophages: The chicken and the egg of immunity. J Innate Immun 6: 716-726, 2014.

34. Inagawa $\mathrm{H}$, Kohchi $\mathrm{C}$ and Soma G: Usefulness of oral administration of lipopolysaccharide for disease prevention through the induction of priming in macrophages. Anticancer Res 34: 4497-4501, 2014. 